\title{
Pengungkapan Diri Anak Tunarungu dalam Kelompok Teater Tujuh di Jakarta
}

\author{
Yola Nahria Mufida, Suzy S. Azeharie \\ Olanahria13@gmail.com,suzya@fikom.untar.ac.id
}

Fakultas Ilmu Komunikasi Universitas Tarumanagara

\begin{abstract}
Human beings are social beings that coexist. Ideas or a message to others are conveyed through communication. In performing communication, a hearing sense is needed to hear the message delivered.Good hearing makes it easier for the creation of a meaning by a person. Things are different when one's condition cannot hear or be deaf. Disturbances on hearing experienced by deaf children will impact verbal abilities so that they use sign language and body language to communicate. Deaf children experience problems of their own especially on communication, it impacts their confidence and tends to shut down. Self-disclosure required deaf children who applied when they were in a social setting. The author conducts research relating to the self-disclosure of deaf children in the group Theatre Seven in Jakarta. The theory the author uses is group communication theory and self-disclosure theory. The author uses a qualitative research approach and case study research method. In this study the author selected five informants for information and data with regard to research topics. The criteria chosen from the author were deaf children in the 8-12-year-old group of Theatre Seven. The results show that there was a self-disclosure of deaf children in the group Theatre Seven. That is confidence, believing in others, sharing information about him or her to others such as experience, feelings, and ideas as well as there is the effectiveness of communication with Indonesia Sign Language (Bisindo) and making communication more efficient.
\end{abstract}

Keywords: deaf children, group communication, self disclosure

\begin{abstract}
Abstrak
Manusia merupakan makhluk sosial yang hidup berdampingan. Gagasan atau suatu pesan kepada orang lain disampaikan melalui komunikasi. Dalam melakukan komunikasi, indera pendengaran dibutuhkan untuk mendengar pesan yang disampaikan. Pendengaran yang baik memudahkan terciptanya suatu makna oleh seseorang. Hal berbeda terjadi bila kondisi seseorang tidak dapat mendengar atau tunarungu. Gangguan pada pendengaran yang dialami anak tunarungu akan berdampak pada kemampuan verbal sehingga mereka menggunakan bahasa isyarat dan bahasa tubuh untuk berkomunikasi. Anak tunarungu mengalami masalah tersendiri terutama pada komunikasi. Hal tersebut berdampak pada kepercayaan diri mereka dan kecenderungan menutup diri. Pengungkapan diri diperlukan anak-anak tunarungu ketika mereka berada di lingkungan sosial. Penulis melakukan penelitian yang berkaitan dengan pengungkapan diri anak tunarungu dalam kelompok Teater Tujuh di Jakarta. Teori yang digunakan penulis adalah teori komunikasi kelompok dan teori pengungkapan diri. Penulis menggunakan pendekatan penelitian kualitatif dan metode penelitian studi kasus. Dalam penelitian ini, penulis memilih lima informan untuk mendapatkan informasi dan data yang berkaitan dengan topik penelitian. Kriteria yang dipilih dari penulis adalah anak tunarungu dalam Kelompok Teater Tujuh yang berusia 8-12 tahun. Hasil penelitian menunjukkan bahwa terjadi pengungkapan diri anak tunarungu dalam kelompok Teater Tujuh yaitu dengan percaya diri, percaya dengan orang lain, berbagi informasi mengenai dirinya kepada orang lain seperti pengalaman, perasaan dan ide. Selain itu, terdapat efektifitas komunikasi dengan Bahasa Isyarat Indonesia (Bisindo) dan membuat komunikasi menjadi efisien.
\end{abstract}

Kata Kunci: anak tunarungu, komunikasi kelompok, pengungkapan diri 


\section{Pendahuluan}

Manusia merupakan makhluk sosial yang saling hidup berdampingan. Ketika menyampaikan gagasan atau suatu pesan kepada orang lain manusia menggunakan cara untuk berkomunikasi. Komunikasi sebagai proses sosial individu-individu dalam menggunakan simbol-simbol untuk menciptakan, menginterpretasikan makna dalam suatu pesan (West dan Turner, 2008).

Dalam melakukan komunikasi, indera pendengaran dibutuhkan untuk mendengar pesan yang disampaikan oleh orang lain. Pendengaran yang baik memudahkan terciptanya makna dari seseorang kepada orang lain. Akan tetapi hal ini berbeda bila kondisi seseorang tidak dapat mendengar atau tunarungu.

Tunarungu merupakan seseorang yang memiliki gangguan pada pendengaran sehingga tidak bisa mendengar secara baik atau bahkan tidak dapat mendengar sama sekali. Gangguan pada pendengaran yang dialami anak tunarungu akan berdampak pada kemampuan verbal dalam komunikasi sehingga mereka menggunakan bahasa isyarat dan bahasa tubuh untuk berkomunikasi. Bahasa isyarat yang digunakan berupa Bahasa Isyarat Indonesia (Bisindo), Sistem Isyarat Bahasa Indonesia (SIBI) dan bahasa isyarat alami yang diajarkan sejak kecil dalam lingkungan rumah.

Tunarungu adalah seseorang yang mengalami kekurangan atau kehilangan kemampuan mendengar yang diakibatkan tidak berfungsinya sebagian atau seluruh alat pendengaran sehingga seseorang tidak dapat menggunakan alat pendengarannya dalam kehidupan sehari-hari (Winarsih, 2007). Secara fisik anak tunarungu terlihat seperti anak-anak normal. Jika mereka mulai berkomunikasi maka terlihat bahwa anak tersebut mengalami gangguan pendengaran. Anak tunarungu mengalami masalah tersendiri terutama pada saat komunikasi. Hal tersebut berdampak pada kepercayaan diri sehingga mereka cenderung menutup diri dari lingkungan sosial dan hanya bersosialisasi dengan sesama penyandang tunarungu. Sementara dengan berkomunikasi seseorang mampu mengungkapkan perasaan dan pikiran mereka secara terbuka tanpa harus mengkhawatirkan situasi dan kondisi.

Anak-anak tunarungu hanya akan berkomunikasi dengan sesamanya sehingga membentuk suatu kelompok. Kelompok merupakan tempat bagi anak tunarungu untuk belajar, berinteraksi dan bersosialisasi yang akan berguna sebagai bekal mereka. Salah satunya adalah kelompok Teater Tujuh atau teater tunarungu. Teater ini merupakan satu-satunya di Indonesia. Teater Tujuh cukup diminati anak tunarungu karena dengan mengikuti teater, anak-anak tunarungu dapat berinteraksi secara langsung antar sesama dan berbagi informasi lebih luas.

Komunikasi nonverbal dilakukan oleh anak tunarungu tetapi bentuk komunikasi mereka berbeda dengan masyarakat lain. Komunikasi yang digunakan anak tunarungu adalah dengan menggunakan bahasa isyarat Indonesia seperti gerak tubuh, gerak bibir dan ekspresi wajah yang disampaikan orang lain.

Pengungkapan diri terjadi ketika seorang individu menyampaikan pesan tentang dirinya sendiri kepada orang lain. Pengungkapan diri tersebut dilakukan secara sadar dan dilakukan dengan sengaja. Pengungkapan diri juga dapat membuat orang lain semakin memahami diri kita dan sebaliknya kita pun semakin memahami orang lain (Azeharie dan Sari, 2015). 


\section{Metode Penelitian}

Penelitian ini menggunakan pendekatan kualitatif dengan pendekatan studi kasus. Penelitian kualitatif adalah penelitian yang bermaksud untuk memahami fenomena tentang apa yang dialami subjek penelitian misalnya perilaku, persepsi, motivasi, tindakan dan lain-lain, secara holistik dan dengan cara deskripsi dalam bentuk kata-kata dan bahasa, pada suatu konteks khusus yang alamiah dan dengan memanfaatkan berbagai metode ilmiah (Moleong, 2009:9). Unit analisis pada penelitian ini adalah pengungkapan diri anak tunarungu dalam kelompok Teater Tujuh di Jakarta. Untuk memperkuat penelitian penulis melakukan in depth interview kepada narasumber, penulis juga melakukan observasi langsung dan studi pustaka.

Pengumpulan data dilakukan dengan metode wawancara, observasi, studi pustaka. Wawancara dilakukan dengan narasumber untuk mengetahui pendapat, ideide, serta mengetahui pengalaman masa lalu sebelum memasuki kelompok Teater Tujuh dan sesudah masuk ke dalam kelompok Teater Tujuh di Jakarta. Penulis melakukan wawancara langsung dengan anak-anak tunarungu di Teater Tujuh Jakarta sebagai data primer penelitian. Data penelitian diperoleh dari narasumber dengan kriteria anak tunarungu dengan umur $8-12$ tahun serta bergabung dengan kelompok Teater Tujuh di Jakarta.

Observasi pasif dilakukan dengan datang ke tempat kegiatan subjek penelitian yaitu Teater Tujuh di Taman Ismail Marzuki Jakarta. Peneliti tidak ikut terlibat dalam kegiatan yang dilakukan oleh subjek yang diamati. Sementara, peneliti menggunakan buku-buku teori yang berkaitan Ilmu Komunikasi yaitu komunikasi kelompok, komunikasi nonverbal, pengungkapan diri, masalah penelitian sebagai sumber data yang relevan dengan penulisan laporan penelitian.

\section{Hasil Temuan dan Diskusi}

Setelah dilakukan observasi dan wawancara dengan narasumber menunjukkan bahwa ada kemudahan saat berkomunikasi menggunakan Bahasa Isyarat Indonesia (Bisindo) dalam kelompok Teater Tujuh. Tidak ada paksaan dalam penggunaan bahasa isyarat tertentu di dalam kelompok Teater Tujuh, karena anak tunarungu diberikan kebebasan dalam menggunakan bahasa isyarat apapun demi kenyamanannya dalam berkomunikasi sepanjang dapat dipahami oleh anggota lain.

Komunikasi kelompok yang dilakukan Teater Tujuh adalah secara nonverbal dengan menggunakan Bisindo, gerak bibir, gestur tubuh dan ekspresi wajah. Hal ini mendukung pesan yang ingin disampaikan antara anak-anak tunarungu dengan pelatih di dalam kelompok Teater Tujuh. 
Gambar 1. Komunikasi dengan Bahasa Isyarat

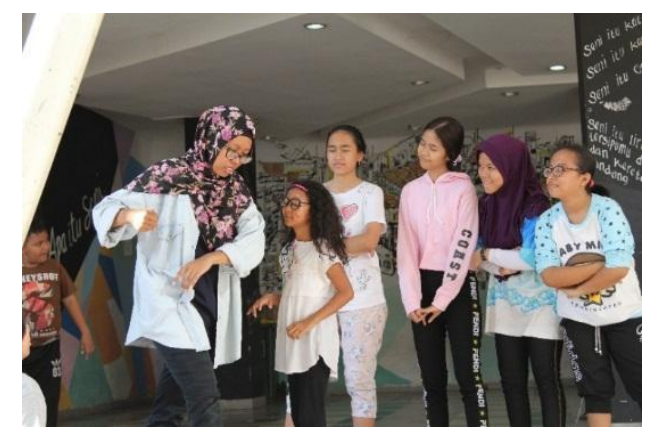

Sumber : Dokumentasi Pribadi pada 9 November 2019

Pelatih juga memberikan peran setelah melihat kemampuan anak-anak tunarungu. Apabila anak tunarungu belum memahami perannya, pelatih akan memperagakan adegan dalam peran tersebut, agar anak-anak tunarungu dapat memahami peran karena ketika berkomunikasi menggunakan bahasa isyarat berupa ekspresi wajah, gestur tubuh, dan gerak bibir.

Dalam melakukan pengungkapan diri, anak tunarungu di Teater Tujuh bersedia mengungkapkan informasi, menyampaikan pendapat, keinginan, ide dan lain-lainnya. Seorang anak tunarungu bernama Reza, menjelaskan bahwa sejak bergabung dengan kelompok Teater Tujuh ia merasa bukan hanya dirinya yang memiliki gangguan pendengaran sehingga ia berani untuk mengungkapkan diri sebagai anak tunarungu. Kepercayaan diri itu juga membuat ia berani dalam mengekspresikan dirinya dalam melakukan pantomim di sekolah.

Selain itu, menurut Nada, pengungkapan diri juga memiliki rasa percaya terhadap orang lain. Percaya bahwa orang yang dihadapi mampu menerimanya sebagai anak tunarungu, dan memahami cara berkomunikasinya. Sedangkan menurut Angga, saat bergabung dengan kelompok Teater Tujuh, pengungkapan diri sebagai anak tunarungu dapat dilakukan oleh teman-teman tunarungu lainnya karena memiliki rasa percaya pada orang lain untuk berbagi masalah pribadi dengan orang lain, hanya pada orang yang benar-benar dekat dengan dirinya atau kepada orang yang disukainya saja.

Gambar 2. Ashley Astera Canada Loverdo Khodiri berinteraksi dengan Temannya

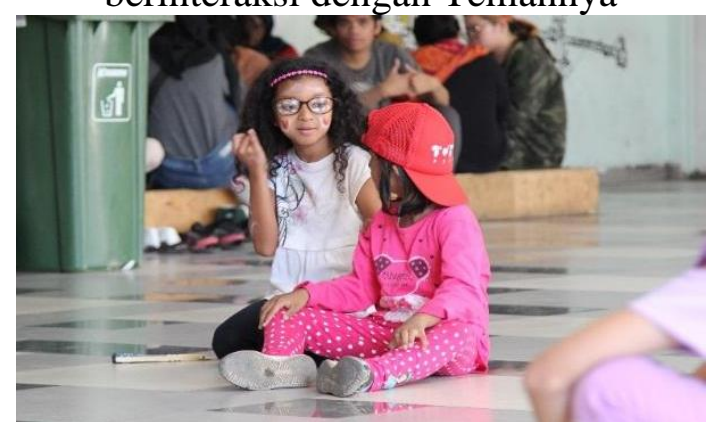

\section{Sumber : Dokumentasi Pribadi pada 9 November 2019}

Dalam teori pengungkapan diri, pengungkapan mengenai informasi diri kita yang biasanya tidak diketahui oleh orang lain. Misalnya memberikan informasi pribadi seperti harapan, ketakutan, perasaan, pikiran dan pengalaman kita serta keterampilan komunikasi yang penting, terutama pada tingkatan hubungan awal untuk 
meningkatkan kepercayaan dan rasa kedekatan, serta dapat menambah harga diri dan keamanan dalam hubungan (Wood, 2013). Terlihat dari pengungkapan diri anak tunarungu dalam kegiatan latihan teater dapat percaya diri, mengungkapkan perasaan, pikiran dan pengalaman serta keterampilan dalam berkomunikasi di kelompok Teater Tujuh.

Dalam fungsi pengungkapan diri anak-anak tunarungu dalam Teater Tujuh adalah percaya diri sendiri dan orang lain baik dengan orang yang memiliki gangguan pendengaran dan pendengaran normal, serta memiliki rasa ketertarikan dalam berkomunikasi dengan orang lain untuk bertukar makna dan menjalin komunikasi yang lebih baik pada orang lain. Hal ini mendukung pada kepercayaan diri anak-anak tunarungu untuk mengungkapkan dirinya sebagai anak tunarungu di lingkungan masyarakat.

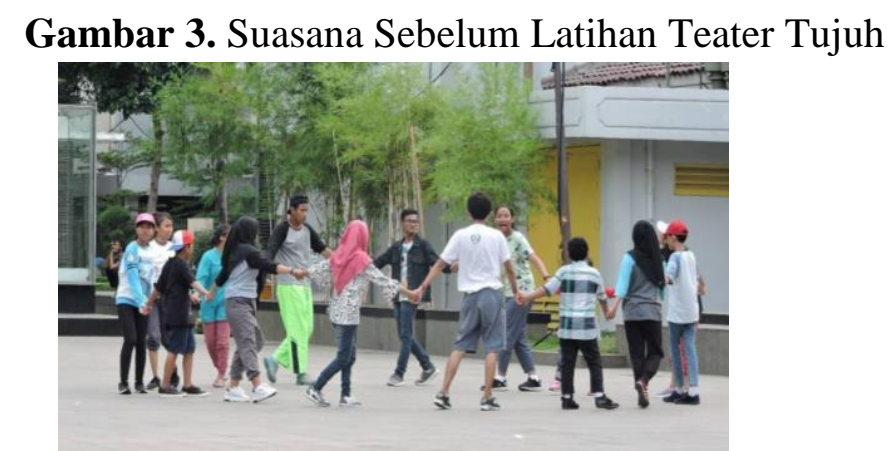

Sumber : Dokumentasi Pribadi pada 10 November 2019

Dimensi pengungkapan diri anak tunarungu dalam kelompok Teater Tujuh memiliki kualitas keterbukaan yang positif. Dengan pengungkapan diri, mereka memiliki kecermatan dan kejujuran untuk mengenal pribadinya lebih baik, dengan memiliki maksud dan tujuan dalam memudahkan berkomunikasi dengan orang lain terutama dengan orang-orang yang memiliki pendengaran normal. Serta keakraban dalam kegiatan di dalam kelompok Teater Tujuh.

Pengungkapan diri dalam kelompok Teater Tujuh memiliki manfaat pada anak-anak tunarungu yaitu dapat memahami dirinya sebagai anak tunarungu, mengatasi masalah dengan rasa tidak takut untuk diterima lingkungan, memperbaiki komunikasi melalui Bisindo agar terjadi komunikasi yang efisien, serta memiliki kedalaman hubungan. Kedalaman hubungan ini terjadi karena membuka diri dengan orang lain dengan rasa kepercayaan pada orang lain serta keakraban dalam keterbukaan diri dengan berbagi informasi mengenai dirinya pada orang lain.

\section{Simpulan}

Bahasa isyarat memudahkan anak-anak tunarungu untuk berkomunikasi dengan orang lain yang memiliki pendengaran normal. Dalam mengatasi kendala dalam berkomunikasi menggunakan Bisindo, pelatih teater memberikan contoh gerakan pemain menggunakan gerak tubuh, ekspresi wajah dan gerak bibir pada anakanak tunarungu untuk membuat mereka paham dan dapat bertukar makna.

Penggunaan komunikasi yang efektif dengan Bisindo untuk berinteraksi dengan pelatih, anggota teater dan orang lain yang memiliki pendengaran normal. Mereka juga menyesuaikan diri dan percaya pada orang lain untuk membuka diri dalam keterbukaan informasi dirinya dengan pelatih dan anggota lainnya. Anak-anak 
tunarungu percaya pada diri sendiri untuk mengungkapkan dirinya sebagai anak tunarungu tanpa rasa takut tidak diterima dilingkungan.

Pengungkapan diri anak tunarungu bertujuan untuk memudahkan berinteraksi dengan orang lain, serta memiliki keakraban dengan anggota kelompok Teater Tujuh Jakarta. Selain itu, mereka mampu mengatasi masalahnya untuk memahami diri sendiri bahwa mereka tidak sendiri mengalami gangguan pendengaran dan mampu melakukan kegiatan seperti orang-orang yang memiliki pendengaran normal.

\section{Ucapan Terima Kasih}

Peneliti mengucapkan banyak terimakasih kepada seluruh pihak yang membantu dalam penulisan jurnal ini dan semua pembaca yang telah membaca jurnal ini.

\section{Daftar Pustaka}

Azeharie, Suzy S \& Wulan Purnamasari (2015). Penyingkapan Diri Ibas Yudhoyono Dalam Instagram Dan Reaksi Ibu Ani Yudhoyono Terhadap Postingan Instagram Ibas. Fakultas Ilmu Komunikasi. Universitas Tarumanagara.

Moleong, Lexy J. (2009). Metode Penelitian Kualitatif. Bandung: Remaja Rosdakarya.

West, Richard dan Lynn H. Turner. (2008). Pengantar Teori Komunikasi Analisis dan Aplikasi. Jakarta : Salemba Humanika.

Winarsih, M (2007). Intervensi Dini Bagi Anak Tunarungu dalam Pemrosesan Bahasa. Departemen Pendidikan dan Kebudayaan. Direktorat Jenderal Pendidikan Tinggi. Direktorat Ketenagaan.

Wood, Julia T. (2012). Communication in Our Lives. Stanford: Concage Learning. 